\title{
L'AMANT DE LA CHINE DU NORD (1991); ROTEIRO ROMANESCO ENTRE CINEMA E LITERATURA
}

\author{
L'AMANT DE LA CHINE DU NORD (1991): SCÉNARIO \\ ROMANESQUE ENTRE CINÉMA ET LITTÉRATURE
}

PONTES GIOVE, Maria do Socorro Aguiar ${ }^{1}$

\begin{abstract}
RESUMO: Este estudo pretende averiguar como L'Amant de la Chine du Nord $[O$ Amante da China do Norte] (1991), de Marguerite Duras, obra que surgiu devido à insatisfação da autora francesa com o filme L'Amant [O amante] (1991), dirigido por Jean-Jacques Annaud, configura-se como uma mistura entre dois gêneros, quais sejam, o roteiro cinematográfico e o romance. Dessa forma, L'Amant de la Chine du Nord (1991) pode ser lido não apenas como um romance, mas também como um roteiro cinematográfico, pois contém elementos correspondentes a ambos os gêneros. Segundo Todorov (1980), um novo gênero nasce a partir da transformação de um ou mais gêneros antigos, seja por inversão, seja por deslocamento ou por combinação. Ao trazer características específicas do roteiro cinematográfico comum, como didascálias, planos e angulações, Marguerite Duras propõe determinada renovação da escrita do romance, criando uma obra que nasce exatamente no entroncamento entre o cinema e a literatura. Esta análise investiga como e por que a combinação de recursos tanto do roteiro cinematográfico quanto do romance, em L'Amant de la Chine du Nord (1991), taz elementos que demonstram a criação uma obra de caráter híbrido.
\end{abstract}

PALAVRAS-CHAVE: Cinema, Literatura, Hibridismo, Roteiro romanesco.

RÉSUMÉ : Cette étude vise à découvrir comment L'Amant de la Chine du Nord (1991), un ouvrage qui a vu le jour en raison de l'insatisfaction de l'auteure française avec le film L'Amant (1991), réalisé par Jean-Jacques Annaud, se configure comme un mélange entre deux genres, à savoir, le scénario cinématographique et le roman. Ainsi, L'Amant de la Chine $d u$ Nord (1991) peut être lu non seulement comme un roman, mais aussi comme un scénario cinématographique, car il contient des éléments correspondant aux deux genres. Selon Todorov (1980), un nouveau genre naît à partir de la transformation d'un ou de plusieurs genres anciens, soit par inversion, soit par déplacement ou par combinaison. En apportant des traits spécifiques du scénario cinématographique commun, tels que les didascalies et des

\footnotetext{
${ }^{1}$ Mestra em Literatura e Práticas Sociais pela Universidade de Brasília (UnB). Doutoranda em Literatura e Práticas Sociais pela mesma instituição. Professora de francês da Secretaria de Educação do Distrito Federal (SEDF). Endereço eletrônico: mlle.pontes82@gmail.com.
}

Jangada | nr. 11, jan/jun, 2018 | ISSN 2317-4722

81 | Pá g in a 
suggestions concernant les plans et les angulations, Marguerite Duras propose un certain renouveau de l'écriture du roman, créant une oeuvre qui naît précisément à l'intersection du cinéma et de la littérature. Cette analyse étudie comment et pourquoi la combinaison des caractéristiques du scénario et du roman, dans L'Amant de la Chine du Nord (1991), apporte des éléments qui démontrent la création d'un ouvrage de caractère hybride.

MOTS-CLÉS : Cinéma, Littérature, Hybridité, Scénario romanesque.

\section{INTRODUÇÃO}

Artista anfíbia e polivalente, Marguerite Duras iniciou a sua carreira com Les impudents [Os insolentes] (1943) e concluiu com C'est tout [No more] (1995), cujo título vaticinava o fim tanto de sua trajetória artística quanto de sua própria existência, ocorrida seis meses após a publicação desta obra. Ao longo de pouco mais de meio século de produção, Marguerite Duras experimentou não apenas artes distintas, tais como literatura, cinema e teatro, mas também gêneros distintos, tais como romances, roteiro cinematográficos e peças de teatro, além de entrevistas e textos críticos. Assim, Marguerite Duras não deixou de refratar, em cada um dos domínios artísticos e gêneros discursivos por ela trabalhados, o savoir-faire adquirido em seu permanente e incansável trânsito interartes, o que proporcionou uma obra monumental e diversificada.

Marguerite Duras iniciou a sua trajetória artística como escritora de romances, sendo os três primeiros Les impudents (1943), La vie tranquille [A vida tranquila] (1944) e Un barrage contre le Pacifique [Barragem contra o Pacífico] (1950). Dezessete anos após a publicação da sua primeira obra, ela adentrará no universo da sétima arte com a redação do roteiro e dos diálogos para o filme Hiroshima mon amour [Hiroshima meu amor] (1960), dirigido por Alain Resnais. Inclusive, é interessante sublinhar que Hiroshima mon amour, pela sua força literária e carga poética, foi o primeiro roteiro cinematográfico a ser publicado na França.

Ao alternar entre a câmera e a máquina de escrever, entre a tela e o papel, Marguerite Duras questionava, constante e infatigavelmente, as fronteiras entre as artes e os gêneros, possibilitando a criação de uma obra de caráter investigativo e experimental. Ademais, por ser uma artista plurivalente da segunda metade do século XX, Marguerite Duras inspirar-se-ia muito na exploração dos recursos da sétima arte para compor uma obra literária transgressora e dificilmente classificável. 
Neste horizonte, convém notar que, no início da história do cinema, diversos cineastas recorreram quer à literatura, quer ao teatro, objetivando enobrecer a arte nascente. Em seus primórdios, o cinema era considerado apenas uma atração de feira, entretenimento barato, destinado a um público analfabeto e de parcos recursos financeiros (SADOUL, 1963). Contudo, com a evolução da linguagem cinematográfica e a consequente autonomização do cinema diante das demais artes, ele passou a influenciar intensamente a literatura, principalmente depois da Segunda Guerra Mundial.

A Nouvelle Vague, movimento artístico do cinema francês dos anos sessenta de caráter contestatório e inovador, teve um papel preponderante no sentido da valorização da sétima arte. A propósito, a ideia segundo a qual o cineasta é o verdadeiro autor da obra cinematográfica foi uma noção forjada na França, depois da Segunda Guerra Mundial, a partir do modelo literário, e por meio dos críticos, e futuros cineastas, que militaram em favor da emancipação do cinema com relação às demais artes, e, principalmente, com relação à literatura (CLÉDER, 2012, p. 59). Vale lembrar que, até então, costumava-se considerar o cinema como uma arte inferior à literatura. Isto posto, Marguerite Duras se inscreve em um contexto histórico propício para experimentar não apenas na literatura, mas também no cinema, produzindo, por meio da coalescência entre ambos os campos artísticos, uma obra fecunda e original.

É interessante perceber que se, por um lado, a literatura inspirou significativamente o cinema nos primeiros balbuciamentos deste, auxiliando-o a elevar-se à categoria de arte, por outro, a arte multimilenar e portadora de grande prestígio, também passará a ser influenciada pela arte nascente. À medida que o cinema se firmou e se autonomizou enquanto arte, elaborando uma linguagem específica, por exemplo, por meio da utilização dos enquadramentos, das angulações e dos movimentos de câmera, passará a influenciar decisivamente as suas irmãs mais velhas, notadamente a literatura. Destarte, resulta interessante pesquisar como se deu a transposição de recursos específicos da linguagem cinematográfica para a literatura.

\section{MARGUERITE DURAS ENTRE CINEMA E LITERATURA}

Em L'Amant de la Chine du Nord (1991), encontramos ecos de uma das primeiras obras de Marguerite Duras, considerada por Perrone-Moisés (1996) como pertencente à 
primeira fase da obra da autora e tributária do romance norte-americano: Un barrage contre le Pacifique (1950). Aliás, a mesma temática também é encontrada na peça de teatro L'Éden cinéma [Eden Cinema] (1977), cujo título manifesta o parentesco com a sétima arte, e no romance L'Amant (1984). Neste sentido, cumpre afirmar que Marguerite Duras costumava sempre retomar a mesma temática, contando-a e recontando-a de diferentes maneiras, fato que caracteriza, a propósito, a produção literária, teatral, cinematográfica e até mesmo crítica de Marguerite Duras.

Ora, Marguerite Duras se posicionava vigorosamente contra a narrativa cinematográfica tradicional. Toda a sua obra cinematográfica, aliás, será um constante questionamento das convenções da gramática cinematográfica dominante. Muitas destas reflexões podem ser encontradas, por exemplo, em Les Yeux Verts [Os olhos verdes] (1987), obra que reúne vários textos críticos sobre cinema, literatura e política, além de crônicas e entrevistas. Se, por um lado, Marguerite Duras questionava o modo convencional de fazer cinema, por outro, aportará influências cinematográficas no seu modo de fazer literatura.

Antes de Marguerite Duras ingressar no cinema, outros diretores tinham adaptado algumas de suas obras, tais como René Clément, que realizou Un barrage contre le Pacifique [Barragem contra o Pacífico] (1958), o qual ela considera como “[...] a mais inacreditável traição"2 (DURAS, 2014, p. 608), e Peter Brook, que dirigiu Moderato Cantabile (1960), do qual Duras (2014, p. 608), também por descontentamento com a transposição cinematográfica, queria ter feito a sua própria versão.

O romance L'Amant (1984) foi escrito em torno de um álbum de fotografias sobre o qual Marguerite Duras deveria escrever. A ausência de uma imagem - fotografia absoluta não fotografada - teria desencadeado a imaginação da autora e a consequente escrita da obra que, num primeiro momento, chamar-se-ia L'Image absolue [A Imagem absoluta] (CLÉDER, 2014, p. 8). Posteriormente, a cine-escritora francesa decidiu chamá-la de L'Amant.

Em 1991, Jean-Jacques Annaud realizará L’Amant, adaptação cinematográfica que Marguerite Duras rechaça por divergir da concepção cinematográfica do cineasta francês. Inclusive, o filme em questão é "[...] estrangeiro ao universo durassiano"” (BORGOMANO, 2010 , p. 50), posto que “[...] trata-se de outro universo, ou de outra visão do cinema e do mundo" (BORGOMANO, 2010, p. 50). Na verdade, Marguerite Duras, numa proposta

\footnotetext{
2 “[...] la plus incroyable trahison". (Tradução minha. Todas as passagens dos textos em francês para o português foram traduzidas por mim).

3 “[...] étranger à l'univers durassien".

4 “[...] il s'agit d'un autre univers, ou d'une autre vision du cinéma et du monde".
} 
cinematográfica radical e transgressora, considerava que o filme ideal de L'Amant seria a leitura do mesmo, feita pela própria autora (CLÉDER, 2014), procedimento do qual ela já tinha lançado mão em obras anteriores, tais como, por exemplo, em todos os seus curtasmetragens (1979): Aurélia Steiner (Vancouver), Aurélia Steiner (Melbourne), Les Mains Négatives e Césarée.

Com efeito, o modo de pensar cinema, de Marguerite Duras, divergia veementemente do modo de fazer cinema dos realizadores que se aventuraram em traduzir em imagens cinematográficas as suas obras literárias. A propósito, Marguerite Duras ingressou no cinema precisamente por discordar da maneira como outros realizadores adaptavam as suas obras (DURAS, 2014, p. 608). Neste horizonte, M.D. ${ }^{5}$ não apenas renovou o fazer cinematográfico, graças às influências literárias, mas também o fazer literário, graças às experiências oriundas da sétima arte.

Dessarte, sendo uma autora que bebeu abundantemente na fonte da sétima arte, Marguerite Duras não hesitou em importar, amplamente, tais experiências para a sua produção literária. Assim, os romances, que pertencem à primeira fase de Marguerite Duras (PERRONE-MOISÉS, 1996), são bastante diferentes dos posteriores às suas experiências cinematográficas, uma vez que estes últimos já se encontram, ampla e intencionalmente, impregnados por influências cinematográficas, como é o caso de L'Amant de la Chine du Nord (1991).

Em 1948, no artigo seminal Naissance d'une nouvelle avant-garde: la caméra-stylo [Nascimento de uma nova Vanguarda: a caméra-stylo], Alexandre Astruc propugnava que "O autor escreve com a sua câmera como um escritor escreve com uma caneta"6 (ASTRUC, 1948, p. 327). Neste sentido, Marguerite Duras soube levar a metáfora da caméra-stylo a consequências inusitadas, proporcionando determinada renovação tanto do fazer cinematográfico quanto do fazer literário.

Vale notar que, entre os anos de 1967 e 1985, M.D. já havia realizado todos os seus filmes (19 no total), sendo La Musica (1967), correalizado por Paul Seban, a obra cinematográfica que inicia este percurso, e Les Enfants [As Crianças] (1985) a que o encerra.

Nesta perspectiva, entendemos L'Amant de la Chine du Nord (1991), por ter vindo à luz após M.D. ter realizado todos os seus filmes e escrito todos os seus roteiros cinematográficos, como uma obra exemplar no que diz respeito ao intercâmbio entre literatura

\footnotetext{
${ }^{5}$ Usaremos a sigla M.D. para nos referirmos à Marguerite Duras.

6 "L'auteur écrit avec sa caméra comme un écrivain écrit avec un stylo".
} 
e cinema. Além disso, é importante sublinhar que Marguerite Duras escreveu L'Amant de la Chine du Nord (1991) por discordar da transposição cinematográfica do realizador francês, propondo um livro que poderia ser o verdadeiro filme de L'Amant (1984). De fato, conforme demonstraremos ao longo deste artigo, em L'Amant de la Chine du Nord (1991), é possível encontrar diversas características tanto do roteiro quanto da linguagem cinematográfica.

\section{L'AMANT DE LA CHINE DU NORD (1991) ENTRE ROMANCE E ROTEIRO: PROPOSTA DE UMA ANÁLISE}

L'Amant de la Chine du Nord (1991) traz ecos da adolescência de M.D.. Trata-se de uma história de amor, ocorrida na antiga Indochina, atual Vietnã, nos anos 1930, entre uma jovem francesa, de apenas 15 anos e meio, e um Chinês rico, doze anos mais velho. No que diz respeito à anuência deste relacionamento, a mãe da garota adota um comportamento ambíguo. Ora, a mãe aceita o amante chinês, por necessitar das ajudas financeiras dele - pois a família beirava à miséria -, ora rejeita-o, exatamente pelo fato de ele ser Chinês e pertencer a uma raça considerada inferior pela mãe. No final da narrativa, a protagonista viaja para a França e o Chinês se casa com uma mulher para quem havia sido prometido pelo pai.

Logo no início de L'Amant de la Chine du Nord (1991), Marguerite Duras afirma: “Eu me tornei novamente uma escritora de romances"7 (DURAS, 1991, p. 12). Ora, esta informação intriga e desestabiliza o leitor, tendo em vista que o romance em questão é perpassado por características tanto do roteiro quanto da linguagem cinematográfica propriamente dita, conforme procuraremos demonstrar ao longo deste artigo.

No começo da narrativa, M.D. lança mão de frases curtas, com informações semelhantes a didascálias teatrais, com vistas a orientar o leitor-espectador ${ }^{8}$ sobre como poderia ser o filme imaginado pela autora, conforme é possível perceber no seguinte trecho:

Uma casa no meio de um pátio de escola. Ela está completamente aberta. Parece uma festa. Ouvem-se Valsas de Strauss e de Franz Lehar, assim como

\footnotetext{
7 "Je suis redevenue un écrivain de romans".

${ }^{8}$ Consideramos que o fruidor de L'Amant de la Chine du Nord (1991) incorpora a um só tempo as funções de leitor e de espectador, tendo em vista que, ao fazer a leitura da obra, ele também deverá construir, em sua mente, o filme imaginado por Marguerite Duras.
} 
Ramona e Nuits de Chine que saem de janelas e portas. A água corre por toda parte, por dentro, por fora9. (DURAS, 1991, p. 13).

Percebemos que a primeira frase, "Uma casa no meio de um pátio de escola"10, não contém verbo, remetendo o leitor-espectador diretamente a uma imagem, que pode ser uma fotografia ou até mesmo um plano cinematográfico. A propósito, vale ressaltar que M.D. opta, em vários momentos da narrativa, de uma sintaxe simples, produzindo frases que, em razão das imagens que evocam, podem ser facilmente traduzidas para a linguagem cinematográfica.

Segundo Todorov (1980, p. 48), o gênero é uma “[...] codificação de propriedades discursivas". Quando escreve uma obra, o escritor tem em mente determinado gênero discursivo, o qual vai modelar o seu trabalho artístico. Assim, os gêneros funcionam, para os autores, como "modelos de escritura" e, para os leitores, como "horizonte de expectativa" (TODOROV, 1980, p. 40).

Sob o prisma do "horizonte de expectativa", os leitores leem o texto em função do sistema de gêneros que eles conhecem, quer a partir da crítica, quer a partir do ensino, quer a partir do sistema de difusão do livro (TODOROV, 1980, p. 49). Na perspectiva dos "modelos de escritura", os autores, para compor as suas obras, partem de gêneros discursivos disponíveis na sociedade (TODOROV, 1980, p. 49).

L'Amant de la Chine du Nord (1991) desestabiliza o leitor (MÜLLER, 2016, p. 92), uma vez que este se percebe impedido de engessar a obra em quaisquer classificações peremptórias, provocando necessariamente uma ruptura com o seu "horizonte de expectativa" (TODOROV, 1980, p. 40). Dessa maneira, ao deparar-se com uma obra que escorrega entre romance e roteiro cinematográfico, o fruidor é impelido a questionar as suas preconcepções tanto acerca do romance quanto acerca do roteiro cinematográfico.

Pelo fato de ir ao cinema, o leitor do século XX é leitor-espectador, diferenciando-se, assim, do leitor dos séculos precedentes. Neste sentido, L'Amant de la Chine du Nord (1991) pressupõe um leitor que, de certa forma, tenha uma bagagem enquanto espectador, a fim de que possa perceber características do cinema, via literatura, presentes na obra.

Marguerite Duras sempre se preocupou com o papel do espectador, não para ser-lhe subserviente ou adaptar-se a gostos moldados e forjados pela lógica do cinema comercial, mas para provocar o refletir. Neste horizonte, Marguerite Duras estabelece uma contraposição

\footnotetext{
9 "Une maison au milieu d'une cour d'école. Elle est complètement ouverte. On dirait une fête. On entend des Valses de Strauss et de Franz Lehar, et aussi Ramona et Nuits de Chine qui sortent des fenêtres et des portes. L'eau ruisselle partout, dedans, dehors".

10 "Une maison au milieu d'une cour d'école".
} 
entre o espectador infantil e o espectador adulto. Enquanto o primeiro vai ao cinema apenas para se distrair, esquecer e fugir da repetição quotidiana, considerando o cinema tão-somente o seu brinquedo e a sua "fortaleza vazia"11 (DURAS, 1987, p. 19), o espectador adulto faz um esforço intelecto-imaginativo para interagir com o filme (DURAS, 1987, p. 20).

Muito embora seja concebido pela própria autora como um romance (Duras, 1991, p. 12), L'Amant de la Chine du Nord (1991) incorpora elementos do roteiro cinematográfico, bem como da linguagem cinematográfica. Inclusive, logo no início da narrativa, M.D. propõe três modos de entender a obra em questão:

$$
\begin{aligned}
& \text { É um livro. } \\
& \text { É um filme. } \\
& \text { É a noite. }{ }^{12} \text { (DURAS, 1991, p. 17). }
\end{aligned}
$$

No excerto acima, o caráter inclassificável da obra salta aos olhos, uma vez que L'Amant de la Chine du Nord (1991) nasce justamente no entroncamento de dois suportes artísticos distintos, que M.D. utilizou permanentemente durante a sua carreira: livro e filme. Aliás, tais palavras vão aparecer inúmeras vezes ao longo da narrativa. $\mathrm{O}$ artigo indefinido "um"13, que se repete duas vezes acompanhando, respectivamente, os substantivos "livro"14 e "filme" 15 , contrasta com o artigo definido "a"16, que acompanha "noite"17. Ora, a metáfora [É a noite] propõe a equivalência entre livro, filme e noite, remetendo ao caráter inclassificável da obra em análise. Além disso, a disposição das frases desta passagem no texto faz lembrar os versos de um poema.

Logo no início da obra, percebemos que algumas frases lembram didascálias teatrais, trazendo informações concernentes ao cenário. De acordo com Mcsill e Schuck (2016, p. 17), o roteiro cinematográfico deve conter indicações precisas sobre o local e o período do dia onde a cena do filme acontecerá. Dito de outra maneira, tais indicações são amplamente utilizadas em roteiros cinematográficos, pois trazem informações precisas, tais como, no caso do excerto a seguir, de data e lugar:

\footnotetext{
11 "Forteresse vide".

12 "C'est un livre. C'est un film. C'est la nuit".

13 "un".

14 "livre".

15 "film".

16 "la".

17 "nuit".
} 
É em 1930.

É o bairro francês.

É uma rua do bairro francês. ${ }^{18}$ (DURAS, 1991, p. 18).

Interessante perceber que L'Amant de la Chine du Nord (1991) contém várias passagens que indicam como ele deveria ser transposto para a tela, além de referências ao uso das câmeras e sugestões no final da obra para o caso de se tornar inspiração para um filme, como o demonstra o seguinte trecho:

As imagens propostas abaixo poderiam servir à pontuação de um filme tirado deste livro. Em nenhum caso, estas imagens - denominadas planos de corte - deveriam "relatar" a narrativa, ou prolongá-la ou ilustrá-la. Elas seriam distribuídas no filme segundo a vontade do diretor e não decidiriam nada na história. As imagens propostas poderiam ser retomadas a qualquer momento, à noite, durante o dia, na estação seca, na estação das chuvas. Etc. ${ }^{19}$ (DURAS, 1991, p. 243).

Aliás, em várias passagens, o texto parece destinar-se diretamente ao cinema. Inclusive, os excertos "A criança sai da imagem. Ela deixa o campo da câmera e o da festa"20 (DURAS, 1991, p. 21, grifos nossos) e "A câmera varre lentamente o que acabamos de ver, então, ela se vira e parte na direção que tomou a criança"21 (DURAS, 1991, p. 21, grifos nossos) indicam que o leitor está diante de um texto não apenas com propriedades literárias, mas também com propriedades cinematográficas, tendo em vista que aparece todo um vocabulário concernente ao cinema: "imagem", "campo da câmera" e "A câmera varre lentamente...". Por intermédio de tal vocabulário, o leitor-espectador pode construir, em sua própria imaginação, aquele que seria o verdadeiro filme de L'Amant, tão-somente imaginado e traduzido em palavras por Marguerite Duras.

Ora, um leitor anterior ao século XX, que não fosse ele mesmo também um espectador, não poderia reconhecer termos como "campo da câmera" 22 ou ainda a frase "A

\footnotetext{
18 “C'est en 1930. C'est le quartier français. C'est une rue du quartier français".

19 "Les images proposées ci-dessous pourraient servir à la ponctuation d'un film tiré de ce livre. En aucun cas ces images - dites plans de coupe - ne devraient « rendre compte » du récit, ou le prolonger ou l'illustrer. Elles seraient distribuées dans le film au gré du metteur en scène et ne décideraient en rien de l'histoire. Les images proposées pourraient être reprises à tout moment, la nuit, le jour, à la saison sèche, à la saison des pluies. Etc.”. 20 "L'enfant sort de l'image. Elle quitte le champ de la caméra et celui de la fête".

21 “'La caméra balaie lentement ce qu'on vient de voir puis elle se retourne et repart dans la direction qu'a prise l'enfant".

22 "Champ de la caméra".
} 
câmera varre"23. Até mesmo, as palavras "imagem" e "câmera", além das inúmeras aparições do verbo "olhar" 24 chamam particularmente a atenção do leitor-espectador, pois demonstram uma íntima relação com a linguagem do roteiro cinematográfico e com a linguagem cinematográfica propriamente dita.

Ademais, L'Amant de la Chine du Nord (1991) é cravejado por frases curtas, o que remete os leitores-espectadores a possíveis imagens (em movimento). Aliás, tais frases curtas, facilmente traduzíveis para a linguagem cinematográfica, poderiam equivaler a rápidos planos de um filme. Por exemplo, no trecho “[...] A criança abre o portão. Fecha-o. Atravessa o pátio vazio. Entra na casa funcional" ${ }^{25}$ (DURAS, 1991, p. 22), notamos uma sequência de quatro frases curtas, sendo que cada uma delas, segundo a leitura aqui proposta, poderia corresponder a um plano cinematográfico. Igualmente, no trecho a seguir, cada frase poderia equiparar-se ao plano de um filme, sendo o ponto final da gramática normativa a transição de um plano para outro da gramática do cinema: "Ele olha para ela. Eles olham um para o outro. Eles sorriem um para o outro. Ele se aproxima"26 (DURAS, 1991, p. 36).

Inclusive, do ponto de vista da linguagem cinematográfica propriamente dita, primeiros planos abundam, quando percebemos o enfoque de um determinado objeto ou de uma determinada parte do corpo de algum personagem, através de enquadramentos mutiladores. Neste sentido, o primeiro plano "[...] faz uma espécie de paisagem expressiva" (AUMONT; MARIE, 2003, p. 241) do(s) elemento(s) focalizado(s). Aliás, diga-se de passagem, o primeiro plano significou uma grande descoberta para a evolução da linguagem cinematográfica, pois possibilitou observar de perto, e de forma detalhada, sobretudo os rostos, o que era impossível antes da invenção do cinematógrafo.

$\mathrm{Na}$ seguinte passagem, um enquadramento aproximado e/ou um primeiro plano poderiam traduzir cinematograficamente a cena de amor entre o amante chinês e a Criança:

A mão dele acaricia o rosto da criança, os lábios, com os olhos fechados [...]"27 (DURAS, 1991, p. 47). Ou, no trecho subsequente, a câmera parece acompanhar os movimentos das mãos do personagem masculino, deslocando-se sobre o seu próprio eixo e fazendo uma panorâmica: "Ele

\footnotetext{
23 "La caméra balaie".

24 "regarder".

25 “[...] L'enfant ouvre le portail. Le referme. Traverse la cour vide. Entre dans la maison de fonction".

26 "Il la regarde. Ils se regardent. Se sourient. Il s'approche".

27 "Sa main caresse le visage de l'enfant, les lèvres, les yeux fermés [...]".
} 
também fechou os olhos quando ele acariciou os olhos dela, os lábios dela. A mão abandona o rosto, desce ao longo do corpo. Às vezes ela para, amedrontada. Depois ela se retira"28 (DURAS, 1991, p. 48).

Já a frase "[...] Há um pouco de medo na sua mão que treme [...]"29 (DURAS, 1991, p. 36) poderia ser traduzida mediante o uso de um plano-detalhe, a fim de revelar, cinematograficamente, o tremor da mão do personagem. Também o trecho: "Ele se vira para ela. Seu sorriso treme [...]"30 (DURAS, 1991, p. 74) poderia ser traduzido por meio de um enquadramento aproximado ou um primeiríssimo plano sobre o rosto do personagem para que o espectador perceba o sorriso trêmulo do personagem masculino.

Importante notar que "on" 31 aparece inúmeras vezes ao longo de L'Amant de la Chine $d u$ Nord (1991). Pensamos que o pronome "on" corresponde à câmera que possibilita o foco narrativo, convidando o leitor-espectador a observar a cena. Dessarte, os olhos do leitorespectador são conduzidos por uma câmera imaginária, sugerida pela presença constante de "on". Por exemplo, nos seguintes excertos, tal asserção se torna evidente: "Perdemo-la de vista. Permanecemos no pátio vazio"32 (DURAS, 1991, p. 22) e "Vemos as dus crianças que observam juntas este mesmo céu. E depois as vemos observá-lo separadamente"33 (DURAS, 1991, p. 32).

Temos a sensação de seguir a personagem principal com uma câmera, confundindo as funções de espectadores e de leitores, conforme é possível perceber neste trecho: "A garota pára. Ela escuta. Nós a vemos escutando. Ela virou a cabeça na direção da música e ela fechou os olhos. O olhar cego está fixo"34 (DURAS, 1991, p. 20).

No trecho abaixo, podemos observar que a palavra livro aparece três vezes, e notamos, também, a presença da palavra cinema que, aliás, aparece inúmeras vezes ao longo da narrativa. Além disso, Marguerite Duras se refere ao livro L'Amant (1984), no qual o amante chinês foi mostrado como um personagem mais frágil e covarde do que em L'Amant de la Chine du Nord (1991). Além de características físicas diferentes, o amante chinês de 1991,

\footnotetext{
28 "Lui aussi a refermé ses yeux quand il a caressé ses yeux à elle, ses lèvres. La main quitte le visage, descend le long du corps. Quelquefois elle s'arrête, effrayée. Puis elle se retire".

29 " [...] Il y a un peu de peur dans sa main qui tremble [...]".

30 "Il se tourne vers elle. Son sourire tremble [...]".

${ }^{31}$ Em francês, "on" é um pronome sujeito que pode corresponder, em português, tanto a "a gente" quanto ao sujeito indeterminado.

32 "On la perd de vue. On reste dans la cour vide".

33 "On voit les deux enfants qui regardent ensemble ce même ciel. Et puis on les voit séparément le regarder".

34 "La jeune fille s'arrête. Elle écoute. On la voit qui écoute. Elle a tourné la tête dans la direction de la musique et elle a fermé les yeux. Le regard aveuglé est fixe".
} 
com mais saúde e beleza, apresenta uma personalidade mais segura e destemida, demonstrando que o personagem do Chinês sofreu transformações do livro de 1984 [L'Amant] para o livro de 1991 [L'Amant de la Chine du Nord]:

Da limusine preta saiu outro homem do que aquele do livro, outro Chinês da Manchúria. Ele é um pouco diferente daquele do livro: ele é um pouco mais robusto do que ele, ele tem menos medo do que ele, mais audácia. Ele tem mais beleza, mais saúde. Ele é mais "para o cinema" do que aquele do livro. E também ele tem menos timidez do que ele diante da criança ${ }^{35}$. (DURAS, 1991, p. 36, grifos nossos).

De acordo com Todorov (1980, p. 37), o escritor é capaz de criar um novo gênero quando elabora o seu projeto artístico, tornando-se um "genoteta". Consideramos que, em virtude de trazer características próprias do roteiro e da linguagem cinematográfica, mesclando-as com as do romance, L'amant de la Chine du Nord (1991) faz de Marguerite Duras uma verdadeira genoteta.

\section{CONSIDERAÇÕES FINAIS}

A partir da segunda metade do século XX, o cinema passou a influenciar decisivamente a literatura, proporcionando a criação de textos originais e perpassados de características da linguagem cinematográfica. Marguerite Duras é uma autora que produziu uma obra exemplar neste sentido, promovendo um intercâmbio frutífero entre cinema e literatura.

Em L'Amant de la Chine du Nord (1991), o leitor-espectador pode sentir a presença constante da câmera durante toda a narrativa, que se, num primeiro momento, é apresentada como romanesca pela própria autora, revelará, num segundo momento, afinidades explícitas com a linguagem do roteiro cinematográfico e com a linguagem cinematográfica propriamente dita, conforme procuramos demonstrar ao longo deste artigo. Dessarte, o leitor-

\footnotetext{
35 "De la limousine noire est sorti un autre homme que celui du livre, un autre Chinois de la Mandchourie. Il est un peu différent de celui du livre: il est un peu plus robuste que lui, il a moins peur que lui, plus d'audace. Il a plus de beauté, plus de santé. Il est plus «pour le cinéma » que celui du livre. Et aussi il a moins de timidité que lui face à l'enfant".
} 
espectador deverá construir, por meio de um esforço intelecto-imaginativo, o filme sugerido pela leitura de L'Amant de la Chine du Nord (1991) e imaginado por Marguerite Duras.

Neste sentido, talvez em razão de ter sido uma das últimas obras da cine-escritora francesa, L'Amant de la Chine du Nord (1991), por meio da mistura de características do romance, do roteiro e da linguagem cinematográfica, pode ser considerado um roteiro romanesco, permitindo ao fruidor uma dupla e enriquecedora experiência estética: a um só tempo a leitura de um romance e a visualização de um filme possível que cabe a ele elaborar... Neste sentido, o fruidor poderá ser o espectador adulto, idealizado por Marguerite Duras, que vai ao cinema não para evadir-se dos seus problemas quotidianos, mas sim para produzir e criar as suas próprias imagens cinematográficas a partir das imagens tão-somente sugeridas pela leitura de uma obra literária deveras desafiadora...

\section{REFERÊNCIAS BIBLIOGRÁFICAS}

AUMONT, J.; MARIE, M. Dicionário Teórico e Crítico de Cinema. (5 ${ }^{\mathrm{a}}$ ed.). São Paulo: Papirus, 2003.

BORGOMANO, M. Marguerite Duras: de la forme au sens. Paris: L'Hamarttan, 2010.

CLÉDER, J. Cinéma Invisible: L'Amant de Marguerite Duras. Nantes : Éditions Nouvelles Cécile Défaut, 2014.

Entre littérature et cinéma: les affinités électives. Paris: Armand Colin, 2012.

DURAS, M.. C'est tout. Paris: P.O.L., 1995.

Hiroshima mon amour. Paris: Gallimard, 1960.

. L'Amant. Paris: Les Éditions de Minuit, 1984.

L'Amant de la Chine du Nord. Paris: Gallimard, 1991.

La vie tranquille. Paris : Gallimard, 1944.

L'Éden Cinéma. Barcelone: Mercure de France, 2014.

Les impudents. France: Gallimard, 1992.

. Les Yeux Verts. Paris: Les Éditions de l'Étoile, 1987.

Outside suivi de Le monde extérieur. Italie: Folio, 2014.

Un barrage contre le Pacifique. Paris: Gallimard, 1950.

MCSILL, J.; SCHUCK, A. Cinema: roteiro. São Paulo: DVS Editora, 2016.

SADOUL, G. História do Cinema Mundial. I Volume. (S.S. Gomes, Trad.). São Paulo: Martins, 1963.

TODOROV, T. Os gêneros do discurso. (E. A. Kossovitch, Trad.). São Paulo: Martins Fontes, 1980.

\section{REFERÊECIAS DA INTERNET}


ASTRUC, A. Naissance d'une nouvelle avant-garde: la caméra-stylo. França. L'Écran Français, n 144 , p. 324-328, mar. 1948. Disponível em:

<http://fgimello.free.fr/documents/seminaire_astruc/camera_stylo-1948.pdf>. Acesso em: 06, jun., 2018.

MÜLlER, A. C. P. L'Amant de la Chine du Nord, de Marguerite Duras: livro, filme, noite. Universidade de São Paulo (São Paulo). Criação \& Crítica, n. 16, p. 91-102, jun. 2016. Disponível em: <http://revistas.usp.br/criacaoecritica〉. Acesso em: 11, jun., 2017.

PERRONE-MOISÉS, L. "O Amante" foi o livro de maior sucesso. Folha de São Paulo (São

Paulo). Disponível em: < http://www1.folha.uol.com.br/fsp/especial/bio/bioduras.htm> Acesso em: 03 jan., 2017.

\section{REFERÊNCIAS FILMOGRÁFICAS}

Berri, C., Burrill, T. \& Tronel J. (Produtores) \& Annaud, Jean-Jacques. (Diretor). (1991). L'Amant [DVD]. França, Inglaterra e Vietnã: Burril Productions, Films A2 \& Renn Productions.

Duras, M. (Produtor) \& Duras, Marguerite. (Diretor). (1979). Aurélia Steiner (Melbourne) [DVD]. França.

Duras, M. (Produtor) \& Duras, Marguerite. (Diretor). (1979). Aurélia Steiner (Vancouver) [DVD]. França.

Duras, M. (Produtor) \& Duras, Marguerite. (Diretor). (1979). Césarée [DVD]. França.

Duras, M. (Produtor) \& Duras, Marguerite. (Diretor). (1979). Les Mains négatives [DVD]. França.

Halfon, S. \& Dauman, A. (Produtores) \& Resnais, Alain. (Diretor). (1959). Hiroshima mon amour [DVD]. França e Japão: Argos Films, Como Films, Daiei Studios \& Pathé Entertainment.

Laurentiis, D. De. (Produtor) \& Clément, René. (Diretor). (1958). Un barrage contre le Pacifique [DVD]. Estados Unidos e Itália: Columbia Pictures Corporation \& Dino De Laurentiis Cinematografica.

Lévy, R. (Produtor) \& Brook, Peter. (Diretor). (1960). Moderato Cantabile [DVD]. Itália e França: Production Iena \& Documento Films.

Pansard-Besson, R. \& Vieille, F. (Produtores) \& Duras, Marguerite. (Diretor). (1985). Les Enfants [DVD]. França: Les Productions Berthemont.

Ploquin, R. (Produtor) \& Duras, Marguerite \& Seban, Paul. (Diretores). (1967). La Musica [DVD]. França: Raoul Ploquin. 